\title{
Hypercapnia does not shorten emergence time from propofol anesthesia: a pilot randomized clinical study
}

\author{
Ki-hyug Kwon, Hansu Bae, Hyun Gu Kang, and Junyong In \\ Department of Anesthesiology and Pain Medicine, Dongguk University Ilsan Hospital, Goyang, Korea
}

Background: The elimination of anesthetic agents is a decisive factor in the emergence from general anesthesia. In this pilot study, we hypothesized that hypercapnia would decrease the emergence time from propofol anesthesia by increasing cardiac output and cerebral blood flow.

Methods: A total of 32 patients were randomly divided into two groups based on the end-tidal carbon dioxide values: 30 $\mathrm{mmHg}$ (the hypocapnia group) and $50 \mathrm{mmHg}$ (the hypercapnia group). Propofol and remifentanil were infused to maintain a bispectral index of 40-50. Remifentanil infusion was stopped $10 \mathrm{~min}$ before the discontinuation of propofol. After cessation of propofol infusion, ventilation settings in the hypocapnia group were maintained constant; a rebreathing tube was connected to the respiratory circuit in the hypercapnia group. The time to spontaneous respiration, eye opening (primary endpoint), mouth opening, and tracheal extubation was recorded and analyzed.

Results: Time to eye opening was 9.7 (1.3) $\mathrm{min}$ in the hypocapnia group and 9.0 (1.0) $\mathrm{min}$ in the hypercapnia group. The difference in the mean times to eye opening between groups was $-0.7 \mathrm{~min}(95 \% \mathrm{CI},-4.0$ to $2.7, \mathrm{P}=0.688)$. On multiple regression analysis, there was a significant difference in the mean time to eye opening between males and females. Females recovered about $3.6 \mathrm{~min}$ faster than males ( $95 \% \mathrm{CI},-6.1$ to $-1.1, \mathrm{P}=0.009$ ).

Conclusions: We could not detect a beneficial effect of hypercapnia on propofol emergence time. Irrespective of hypercapnia, females seemed to recover faster than males.

Keywords: Bispectral index; Emergence; Hypercapnia; Propofol.

Corresponding author: Junyong In, M.D., Ph.D.

Department of Anesthesiology and Pain Medicine, Dongguk University Ilsan Hospital, 27, Dongguk-ro, Ilsandong-gu, Goyang 10326, Korea Tel: 82-31-961-7869, Fax: 82-31-961-7864

Email: dragona1@dumc.or.kr

ORCID: https://orcid.org/0000-0001-7403-4287

Received: March 24, 2017.

Revised: June 17, 2017 (1st); September 4, 2017 (2nd); September 29, 2017 (3rd).

Accepted: November 6, 2017.

Korean J Anesthesiol 2018 June 71(3): 207-212 https://doi.org/10.4097/kja.d.18.27068

\section{Introduction}

The elimination of anesthetic agents, especially from the brain, is a decisive factor in the emergence from general anesthesia. Rapid elimination of anesthetic agents from the brain enables faster emergence. In case of volatile anesthetics, many studies have reported on the effect of hyperventilation and hypercapnia [1-5].

Propofol has gained wide acceptance among anesthesiologists due to its favorable induction characteristics, including its rapid onset time and fast elimination half-life [6]. Rapid elimination of propofol from the blood and brain may be expected to shorten the emergence time. Hypercapnia increases cardiac output (CO) and cerebral blood flow (CBF) [2]. Previous studies have shown

(c) This is an open-access article distributed under the terms of the Creative Commons Attribution Non-Commercial License (http://creativecommons.org/ licenses/by-nc/4.0/), which permits unrestricted non-commercial use, distribution, and reproduction in any medium, provided the original work is properly cited. 
that increased CO following administration of dopamine, norepinephrine, epinephrine, or ephedrine during the maintenance phase of anesthesia is related to a lower blood concentration of propofol and higher bispectral index (BIS) values [7-11]. Therefore, hypercapnia could promote propofol elimination from the blood and the brain and, in turn, shorten the emergence time.

We carried out this pilot study because only a few clinical studies have investigated the relationship between hypercapnia and emergence time with propofol anesthesia. We aimed to assess study feasibility and treatment effect of hypercarbia on emergence time from propofol anesthesia; in addition, we intended to estimate a sample size required for the main study. We hypothesized that the emergence time from propofol anesthesia in patients with hypercapnia would be different from those with hypocapnia. We aimed to compare time to eye opening, time to mouth opening, and time to tracheal extubation in patients with hypo- and hypercapnia and assess outcomes.

\section{Materials and Methods}

After approval from the Institutional Review Board, adult patients aged 20-60 years, with American Society of Anesthesiology physical status 1 to 2 , were informed of the method and purpose of this prospective, randomized, and controlled clinical pilot research. Written consent was obtained from all participants. There were 42 participants, 26 men and 16 women. We excluded patients with psychiatric, pulmonary, cardiac, endocrinal, neuromuscular, hepatic, and neurological diseases or with a history suggestive of such illnesses. Smokers, patients on regular sedatives or other medication likely to affect the study, those who had been under general anesthesia within the past month or had a body mass index of $30 \mathrm{~kg} / \mathrm{m}^{2}$ or more were also excluded. All patients underwent elective orthopedic surgery of the hand or elbow under general anesthesia lasting from 1 to 3 h from January 2012 to June 2013. The protocol for this study has been registered with Clinicaltrials.gov, and the registration number is NCT01531491.

A random allocation sequence was generated with Microsoft Excel 2010. Allocation into groups was made by opening opaque sealed envelopes. Patients were randomly divided into two groups based on end-tidal carbon dioxide $\left(\mathrm{ETCO}_{2}\right)$ levels: $30 \mathrm{mmHg}$ (the hypocapnia group) or $50 \mathrm{mmHg}$ (the hypercapnia group) immediately prior to emergence from propofol anesthesia. Patients were blinded to the group allocation. To blind the physician who provided anesthetic care to the groups, $\mathrm{ETCO}_{2}$ was monitored with a separate monitoring device (SAM module, Solar8000M, GE Healthcare, USA). A blinded third investigator recorded the data during emergence. Patients and the data analyst were also not aware of the treatment allocation.

No premedication was administrated. In the operating room, routine monitoring was commenced, including non-invasive blood pressure, electrocardiogram, pulse oximetry and BIS sensors. After pre-oxygenation with $100 \%$ oxygen with a fresh gas flow of $6 \mathrm{~L} / \mathrm{min}$, anesthesia was induced with propofol $2 \mathrm{mg} / \mathrm{kg}$, remifentanil $1 \mu \mathrm{g} / \mathrm{kg}$, and a non-depolarizing neuromuscular blocking agent. Intubation was carried out with $7.5 \mathrm{~mm}$ ID (internal diameter) tubes in men and $7.0 \mathrm{~mm}$ ID tubes in women. During the maintenance phase, a fresh gas flow of $2 \mathrm{~L} / \mathrm{min}$ with fractional inspired oxygen concentration of 0.4 and propofol infusion at $120 \mu \mathrm{g} / \mathrm{kg} / \mathrm{min}$ were administered. Remifentanil was infused at a dose of 0.1 to $0.25 \mu \mathrm{g} / \mathrm{kg} / \mathrm{min}$ to maintain a BIS value of 40-50. Patients in whom the BIS values could not be maintained within this range with remifentanil infusion were excluded from the study. The respiratory rate was set at 10 breaths/ min, and the tidal volume was controlled to maintain $\mathrm{ETCO}_{2}$ at $30 \mathrm{mmHg}$ during surgery.

Remifentanil infusion was discontinued $10 \mathrm{~min}$ prior to discontinuation of propofol. Following this, $0.4 \mathrm{mg}$ of glycopyrrolate and $15 \mathrm{mg}$ of pyridostigmine were administered, and a train-of-four ratio equal to or greater than 0.9 was confirmed. The fresh gas flow was increased to $6 \mathrm{~L} / \mathrm{min}$ with $100 \%$ oxygen. Emergence began when the administration of propofol was discontinued. The propofol infusion line was connected directly to the intravenous catheter using a three-way stopcock.

During emergence, no modifications were made to the ventilation settings in the hypocapnia group. In the hypercapnia group, a rebreathing tube (about $750 \mathrm{ml}$ ) was connected between the corrugated tube and the endotracheal tube to achieve an $\mathrm{ETCO}_{2}$ of $50 \mathrm{mmHg}$ (Fig. 1).

The time at which the patient started coughing or the $\mathrm{ETCO}_{2}$ level began to change on the capnography was considered as the 'time to spontaneous respiration' and recorded. Patients were asked to open the eyes every $30 \mathrm{~s}$ after the discontinuation of propofol. The time to eye opening was recorded; following this, they were asked to open the mouth, and the time was recorded as time to mouth opening. When spontaneous respiratory efforts were adequate, extubation was carried out (time to tracheal extubation), and then the patient was transfered to the post-anesthesia care unit. At every step of emergence, the time taken from

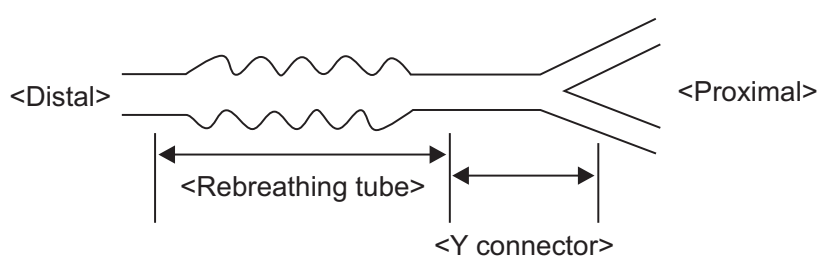

Fig. 1. Rebreathing device. The distal part of the rebreathing tube was connected to the patient and the proximal part was connected to a Y-type connector of the corrugated tube. The diameter of rebreathing tube was 1 $\mathrm{cm}$ and the length was $12-15 \mathrm{~cm}$. 
the discontinuation of propofol to appropriate patient responses was recorded. $\mathrm{ETCO}_{2}$ values and BIS scores were recorded the time of eye opening and tracheal extubation. Pre-emergence BIS values were recorded at the time of discontinuation of propofol.

Being a pilot study, we did not estimate sample size. The primary endpoint was time to eye opening after discontinuation of propofol. We expected to detect a difference in mean time to eye opening of $5 \mathrm{~min}$ [4]. Secondary endpoints were time to spontaneous respiration, time to mouth opening, and time to tracheal extubation. Differences in emergence pattern between males and females between the two groups were compared using the Fisher's exact test. According to the results of the Shapiro-Wilk test for the normality test, age, height, weight, body temperature, hemoglobin, anesthetic time, time to eye opening, time to spontaneous respiration, time to mouth opening, and time to tracheal extubation were compared using a student's $t$-test. Pre-emergence BIS and the total dose of remifentanil and propofol infused were compared using the Mann-Whitney $U$ test.

The time to eye opening was analyzed with a multiple linear regression using sex, age, anesthesia time, and initial BIS as variables. Backward stepwise variable selection was applied. We used a scatter plot to check the linearity between the independent and dependent variables, a QQ plot for normality, Durbin-Watson test for independency. Homoscedasticity was checked using a scatter plot. Collinearity of the explanatory variables was also evaluated with variable inflation factors. Data were presented as mean $(95 \% \mathrm{CI})$ or median $(1 \mathrm{Q}, 3 \mathrm{Q})$. A P value $<0.05$ indicated statistical significance. All statistical calculations were made using SAS (version 9.3, SAS Institute Inc., USA).

\section{Results}

Thirty out of 42 patients completed the study (Fig. 2). No significant difference was observed between groups, in demographic characteristics and the duration of anesthesia. The total dose of remifentanil and propofol administered was similar
(Table 1). The median (1Q, 3Q) $\mathrm{ETCO}_{2}$ level was $31(29,32)$ $\mathrm{mmHg}$ in the hypocapnia group and $51(49,52) \mathrm{mmHg}$ in the hypercapnia group at the time of eye opening $(\mathrm{P}<0.001)$.

The mean time to eye opening was $9.7 \mathrm{~min}$ in the hypocapnia group and $9.0 \mathrm{~min}$ in the hypercapnia groups $(\mathrm{P}=0.688)$ without any difference between them $(-0.7 \mathrm{~min}, 95 \% \mathrm{CI},-4.0$ to 2.7 min; $\mathrm{P}=0.645$ ).

There was no statistically significant difference in secondary outcomes such as time to spontaneous respiration $(\mathrm{P}=0.645)$, time to mouth opening ( $\mathrm{P}=0.576)$, and time to tracheal extubation ( $\mathrm{P}=0.447)$ (Table 2).

Sex and pre-emergence BIS were found to be associated with emergence on multiple regression analysis. Females recovered about $3.6 \min (95 \% \mathrm{CI},-6.1$ to $-1.1 ; \mathrm{P}=0.009)$ faster than males. Higher initial BIS was related to an earlier recovery from the propofol anesthesia ( $2.2 \mathrm{~min}$; $95 \% \mathrm{CI},-3.2$ to $-1.2 \mathrm{~min}$; $\mathrm{P}<$ 0.001 ) (Table 3 ). It means that if the initial BIS is 10 points high-

Table 1. Patients' Characteristics

\begin{tabular}{|c|c|c|c|}
\hline Variable & $\begin{array}{l}\text { Hypocapnia } \\
\text { group }(\mathrm{n}=15)\end{array}$ & $\begin{array}{l}\text { Hypercapnia } \\
\text { group }(\mathrm{n}=15)\end{array}$ & $\mathrm{P}$ value \\
\hline $\operatorname{Sex}(M / F)^{*}$ & $10 / 5$ & $11 / 4$ & 1.000 \\
\hline Age (yr) & $37(8)$ & $41(9)$ & 0.165 \\
\hline Height $(\mathrm{cm})$ & $169(10)$ & $166(9)$ & 0.368 \\
\hline Weight (kg) & $66.9(14.0)$ & $66.3(12.4)$ & 0.902 \\
\hline Body temperature $\left({ }^{\circ} \mathrm{C}\right)$ & $36.4(0.4)$ & $36.6(0.3)$ & 0.123 \\
\hline $\mathrm{Hb}(\mathrm{g} / \mathrm{dl})$ & $14.1(3.6)$ & $14.4(3.2)$ & 0.632 \\
\hline Anesthetic time (min) & $99(36)$ & $107(38)$ & 0.557 \\
\hline Pre-emergence $\mathrm{BIS}^{\dagger}$ & $46(39,53)$ & $43(36,48)$ & 0.457 \\
\hline $\begin{array}{l}\text { Total infused } \\
\quad \text { remifentanil }(\mu \mathrm{g})^{\dagger}\end{array}$ & $1250(1000,1250)$ & $1250(1000,1275)$ & 0.447 \\
\hline $\begin{array}{l}\text { Total infused } \\
\text { propofol }(\mathrm{mg})^{\dagger}\end{array}$ & $1000(770,1100)$ & $960(750,1140)$ & 0.913 \\
\hline
\end{tabular}

Values are expressed as mean (SD), median (1Q, 3Q), or number of patients. Hypocapnia: End-tidal carbon dioxide of $30 \mathrm{mmHg}$, Hypercapnia: End-tidal carbon dioxide of $50 \mathrm{mmHg}$, Pre-emergence BIS: Initial bispectral index value at the discontinuation of propofol. ${ }^{*}$ Fisher's exact test, ${ }^{\dagger}$ Mann-Whitney U test.

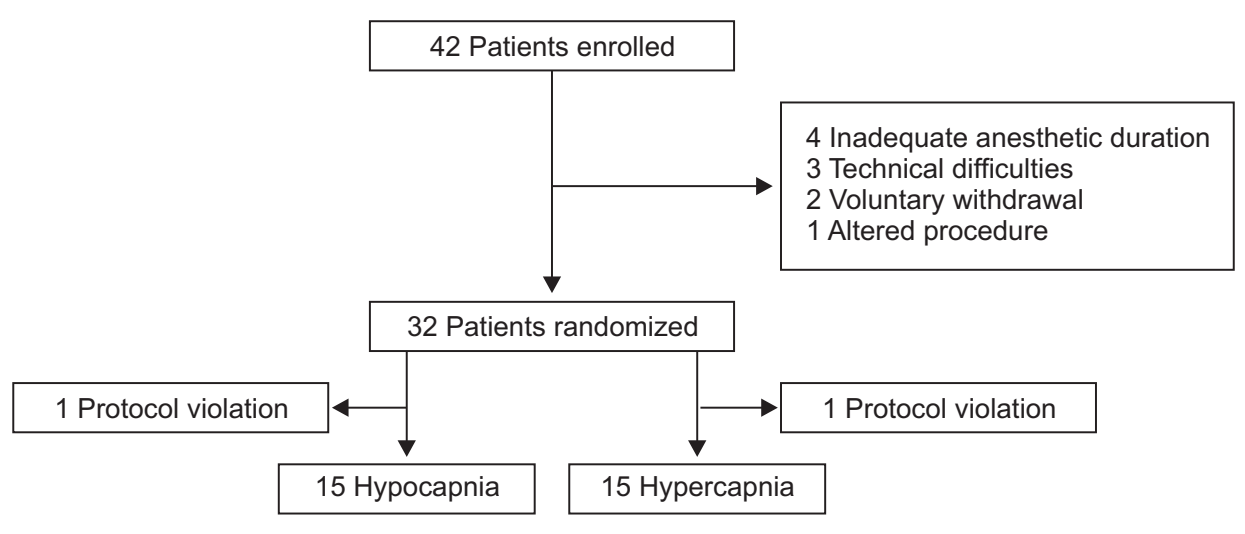

Online access in http://ekja.org
Fig. 2. CONSORT flow chart. 
Table 2. Mean Time of Emergence Events and Difference between the Hypocapnia and Hypercapnia Groups

\begin{tabular}{lcrccc}
\hline $\begin{array}{c}\text { Emergence } \\
\text { events }\end{array}$ & $\begin{array}{c}\text { Hypocapnia } \\
\text { group } \\
(\mathrm{n}=15)\end{array}$ & $\begin{array}{c}\text { Hypercapnia } \\
\text { group } \\
(\mathrm{n}=15)\end{array}$ & $\begin{array}{c}\text { Difference } \\
\text { (95\% CI) }\end{array}$ & P value \\
\hline $\begin{array}{c}\text { Spontaneous } \\
\text { respiration }\end{array}$ & $8.6(1.2)$ & $7.9(1.0)$ & $-0.7(-4.0$ to 2.5$)$ & 0.645 \\
$\begin{array}{l}\text { Eyes opening } \\
\text { Mouth opening }\end{array}$ & $9.7(1.3)$ & $9.0(1.0)$ & $-0.7(-4.0$ to 2.7$)$ & 0.688 \\
$\begin{array}{l}\text { Tracheal } \\
\text { extubation }\end{array}$ & $11.5(1.3)$ & $9.4(1.0)$ & $-0.9(-4.4$ to 2.5$)$ & 0.576 \\
\hline
\end{tabular}

Values (min) are expressed as mean (SE). Hypocapnia: End-tidal carbon dioxide of $30 \mathrm{mmHg}$, Hypercapnia: End-tidal carbon dioxide of 50 $\mathrm{mmHg}$.

er at the end of propofol anesthesia, eye opening would occur 2.2 min earlier. The explanatory power $\left(\mathrm{r}^{2}\right)$ of this regression model was $48.5 \%$.

\section{Discussion}

In this study, we hypothesized that hypercapnia, by increasing $\mathrm{CO}$ and $\mathrm{CBF}$, would shorten emergence time from propofol anesthesia. Time to eye opening was 9.7 (1.3) $\mathrm{min}$ in the hypocapnia group and 9.0 (1.0) $\mathrm{min}$ in the hypercapnia group. Additionally, on multiple regression analysis, a statistically significant difference was observed between males and females in times to eye opening.

We conceptualized a difference in the mean time to eye opening of $5 \mathrm{~min}$, which we deemed to be clinically significant [4]. However, the difference was only $-0.7 \mathrm{~min}$ (95\% CI, -4.0 to 2.7), which was neither statistically nor clinically significant ( $P$ $=0.688$ ). Therefore, the study methodology needs to be modified to augment the effect of hypercapnia on emergence time. Hypercapnia induced at the time of discontinuation of propofol infusion, combined with earlier cessation of remifentanil infusion and/or administration of catecholamine infusions, may be considered.

We recruited 42 patients who were eligible for the study; 15 patients completed the study in each group. However, we found that the sample size $(n=15)$ we estimated was adequate for a full study. The sample size was estimated based on a difference in mean times to eye opening of $5 \mathrm{~min}$, with two standard deviations of 3.8 and $5.0 \mathrm{~min}$ and power of 0.8 at a two-tailed significance level of 0.05 . Hence, we concluded that further study regarding the effect of hypercapnia on emergence time with a larger sample size may not be required.

Propofol is rapidly metabolized in the liver, but its clearance exceeds the hepatic blood flow and extrahepatic metabolism has been suggested to occur. The kidneys play an important role in elimination, accounting for up to $30 \%$ of the extrahepatic
Table 3. Independent Predictors of Time to Eyes Opening

\begin{tabular}{lcccr}
\hline Variable $(\mathrm{n}=30)$ & Estimate $(\mathrm{min})$ & SE & $95 \% \mathrm{CI}$ & P value \\
\hline Sex of female & -3.6 & 1.3 & -6.1 to -1.1 & 0.009 \\
$\begin{array}{l}\text { Pre-emergence BIS } \\
\text { per 10 points }\end{array}$ & -2.2 & 0.5 & -3.2 to -1.2 & $<0.001$ \\
& & & & \\
\hline
\end{tabular}

Pre-emergence BIS: Bispectral index at the discontinuation of propofol, SE: standard error of the estimate. Multiple linear regression analysis was conducted.

metabolism $[12,13]$. Propofol is also eliminated by the lungs, resulting in a $20-30 \%$ decrease in the blood levels $[14,15]$. Thus, an increase in CO may decrease the serum concentration of propofol by increasing the blood flow to organs that eliminate the drug.

Hypercapnia increases CBF, and therefore, it may accelerate the rate of propofol clearance from the brain, similar to volatile anesthetics $[1,16]$. An increase in CO due to hypercapnia decreases the propofol concentration in the blood while increasing the cerebral capillary/tissue diffusion gradient. Therefore, hypercapnia may be important in the rapid clearance of propofol from the brain. Hypercapnia initially causes a decrease in CO and an increase in CBF. However, by increasing venous return, eventually the overall effect of hypercapnia is an increase in CO and CBF with propofol anesthesia [11,17-19]. Without any modification of the ventilation settings, hypercapnia was achieved by connecting a rebreathing tube, because propofol is not exhaled through the lungs, unlike volatile anesthetics.

A more rapid emergence time in females has also been shown in previous studies [20,21]. It is speculated that females have a lower sensitivity to propofol or are capable of metabolizing propofol more rapidly than males. Choong et al. [22] reported that propofol was metabolized by UDP-glucuronosyltranferase $1 \mathrm{~A} 9$ and cytochrome P-450 enzyme 2B6. Although sex is regarded as an unrelated factor to the gene expression of these enzymes, women have faster metabolic rates of these enzymes than men [22]. It is reasonable to assume that the influences of sex on the mean time of eye opening would be significant statistically, but not clinically, because the difference was only 3.6 min. However, since the lower limit of the $95 \%$ CI was $-6.1 \mathrm{~min}$, we could assume that the influences of sex on the mean time to eye opening may be plausible.

Although higher initial BIS values were related to an earlier recovery from the propofol anesthesia, it is reasonable to assume that an increase by 10 points may not be clinically significant because the 95\% CI did not show a difference of $5 \mathrm{~min}$ in the mean times to eye opening.

This pilot study has several limitations. First, pre-induced hypercapnia before the discontinuation of propofol would enable a further increase in $\mathrm{CO}$ and $\mathrm{CBF}$ during recovery, which may meaningfully shorten the emergence time. Measuring $\mathrm{CO}$ and 
CBF would also be helpful to understand the relationship between the hypercapnia and emergence time. Second, we stopped the remifentanil infusion $10 \mathrm{~min}$ before discontinuing propofol. Even though remifentanil is eliminated rapidly from the blood, this may still have influenced the time to recovery. Third, assuming that there may be sex differences in the metabolism of propofol, further studies are required to address this possibility. Lastly, we did not measure the plasma concentration of propofol in this study because CO itself changes the blood propofol concentration, and we assumed that hypercapnia could shorten the emergence time. However, for more accurate results, blood propofol concentration needs to be measured in future studies.
In conclusion, in this pilot study, we could not detect a beneficial effect of hypercapnia on emergence times during recovery from propofol anesthesia. In addition, irrespective of hypercapnia, females tend to recover faster than males.

\section{ORCID}

Ki-hyug Kwon, https://orcid.org/0000-0001-7766-7178

Hansu Bae, https://orcid.org/0000-0002-3002-0550

Hyun Gu Kang, https://orcid.org/0000-0001-8416-8414

Junyong In, https://orcid.org/0000-0001-7403-4287

\section{References}

1. Gopalakrishnan NA, Sakata DJ, Orr JA, McJames S, Westenskow DR. Hypercapnia shortens emergence time from inhaled anesthesia in pigs. Anesth Analg 2007; 104: 815-21.

2. Sakabe T, Matsumoto M. Effects of anesthetic agents and other drugs on cerebral blood flow, metabolism, and intracranial pressure. In: Cottrell and Young's Neuroanesthesia. 5th ed. Edited by Cottrell J, Young W: Philadelphia, Mosby/Elsevier. 2010, pp 78-94.

3. Sakata DJ, Gopalakrishnan NA, Orr JA, White JL, Westenskow DR. Hypercapnic hyperventilation shortens emergence time from isoflurane anesthesia. Anesth Analg 2007; 104: 587-91.

4. Sakata DJ, Gopalakrishnan NA, Orr JA, White JL, Westenskow DR. Rapid recovery from sevoflurane and desflurane with hypercapnia and hyperventilation. Anesth Analg 2007; 105: 79-82.

5. Sasano H, Vesely AE, Iscoe S, Tesler JC, Fisher JA. A simple apparatus for accelerating recovery from inhaled volatile anesthetics. Anesth Analg 2001; 93: 1188-91.

6. Kizilcik N, Menda F, Bilgen S, Keskin O, Koner O. Effects of a fentanyl-propofol mixture on propofol injection pain: a randomized clinical trial. Korean J Anesthesiol 2015; 68: 556-60.

7. Andrzejowski J, Sleigh JW, Johnson IA, Sikiotis L. The effect of intravenous epinephrine on the bispectral index and sedation. Anaesthesia 2000; 55: 761-3.

8. Kurita T, Morita K, Kazama T, Sato S. Influence of cardiac output on plasma propofol concentrations during constant infusion in swine. Anesthesiology 2002; 96: 1498-503.

9. Myburgh JA, Upton RN, Grant C, Martinez A. Epinephrine, norepinephrine and dopamine infusions decrease propofol concentrations during continuous propofol infusion in an ovine model. Intensive Care Med 2001; 27: 276-82.

10. Takizawa D, Nishikawa K, Sato E, Hiraoka H, Yamamoto K, Saito S, et al. A dopamine infusion decreases propofol concentration during epidural blockade under general anesthesia. Can J Anaesth 2005; 52: 463-6.

11. Upton RN, Ludbrook GL, Grant C, Martinez AM. Cardiac output is a determinant of the initial concentrations of propofol after shortinfusion administration. Anesth Analg 1999; 89: 545-52.

12. Takizawa D, Hiraoka H, Goto F, Yamamoto K, Horiuchi R. Human kidneys play an important role in the elimination of propofol. Anesthesiology 2005; 102: 327-30.

13. Takizawa D, Hiraoka H, Nakamura K, Yamamoto K, Horiuchi R. Propofol concentrations during the anhepatic phase of living-related donor liver transplantation. Clin Pharmacol Ther 2004; 76: 648-9.

14. Kuipers JA, Boer F, Olieman W, Burm AG, Bovill JG. First-pass lung uptake and pulmonary clearance of propofol: assessment with a recirculatory indocyanine green pharmacokinetic model. Anesthesiology 1999; 91: 1780-7.

15. Reekers M, Boer F, Vuyk J. Basic concepts of recirculatory pharmacokinetic modelling. Adv Exp Med Biol 2003; 523: 19-26.

16. Cenic A, Craen RA, Howard-Lech VL, Lee TY, Gelb AW. Cerebral blood volume and blood flow at varying arterial carbon dioxide tension levels in rabbits during propofol anesthesia. Anesth Analg 2000; 90: 1376-83.

17. Akça O, Doufas AG, Morioka N, Iscoe S, Fisher J, Sessler DI. Hypercapnia improves tissue oxygenation. Anesthesiology 2002; 97: 801-6.

18. Walley KR, Lewis TH, Wood LD. Acute respiratory acidosis decreases left ventricular contractility but increases cardiac output in dogs. Circ Res 1990; 67: 628-35.

19. Weber T, Tschernich H, Sitzwohl C, Ullrich R, Germann P, Zimpfer M, et al. Tromethamine buffer modifies the depressant effect of permissive hypercapnia on myocardial contractility in patients with acute respiratory distress syndrome. Am J Respir Crit Care Med 2000; 162: 1361-5.

20. Apfelbaum JL, Grasela TH, Hug CC Jr, McLeskey CH, Nahrwold ML, Roizen MF, et al. The initial clinical experience of 1819 physicians in 
maintaining anesthesia with propofol: characteristics associated with prolonged time to awakening. Anesth Analg 1993; 77(4 Suppl): S10-4.

21. Gan TJ, Glass PS, Sigl J, Sebel P, Payne F, Rosow C, et al. Women emerge from general anesthesia with propofol/alfentanil/nitrous oxide faster than men. Anesthesiology 1999; 90: 1283-7.

22. Choong E, Loryan I, Lindqvist M, Nordling Å, el Bouazzaoui S, van Schaik RH, et al. Sex difference in formation of propofol metabolites: a replication study. Basic Clin Pharmacol Toxicol 2013; 113: 126-31. 